\title{
COMPARISON OF REMOTE SITE AND BASEMENT RECORDS AS EXCITATION OF THE VOGEL BUILDING
}

\author{
G.H. McVerry ${ }^{(1)}$
}

Presented at the Third South Pacific Regional Conference on Earthquake Engineering, Wellington, May 1983.

\section{SYNOPSIS :}

Two sets of digitized earthquake records from the 17-storey reinforced concrete Vogel building in Wellington show considerable differences between the accelerations recorded by the basement and remote site instruments fifty metres apart. The records obtained on the massive box foundation are considerably attenuated for most frequencies above $1 \mathrm{~Hz}$, with peak horizontal accelerations ranging from $54 \%$ to $85 \%$ of the remote site values. Better matches of the measured responses are achieved using the basement records rather than the remote site records as the ground acceleration excitation applied to linear models derived using systematic identification techniques.

\section{INTRODUCTION :}

The analysis of two sets of digitized accelerograms from the 17-storey reinforced concrete Vogel building in Wellington provides an excellent example of the type of information which can be gained by instrumenting structures with strong-motion earthquake accelerographs. In both the Central North Island earthquake of 5 January 1973 and the cook Strait earthquake of 18 January 1977, the accelerations measured in the massive box foundation of the Vogel building were considerably attenuated with respect to those recorded on the "free-field" instrument 50 metres away for most frequencies above $1 \mathrm{~Hz}$ (3).

For these records, which represent moderate, non-damaging response of the structure with peak horizontal accelerations of $0.10 \mathrm{~g}$ in 1973 and $0.17 \mathrm{~g}$ in 1977, excellent reproductions of the measured responses were caluclated by subjecting simple linear models of the structure to the recorded basement and free-field acceleration excitations. only two modes in each direction were required to match the horizontal acceleration responses recorded at the 8 th floor and 14 th (top) floor levels when the values of the periods, dampings and participation factors were determined directly from the earthquake records using systematic identification techniques $(11,12)$. Better matches of the recorded acceleration responses were achieved using the attenuated basement records rather than the remote site records as the ground acceleration excitation, although the

(I) Physics and Engineering Laboratory, DSIR, Private Bag, Lower Hutt matches with both were very good. This result is of relevance to ground motion recording for determining "design earthquakes".

The structural instrumentation in the Vogel building forms part of the New Zealand strong-motion accelerograph network (7) operated by the Engineering Seismology section of the Physics and Engineering Laboratory (PEL), DSIR. The network which now includes 125 time-base three-component acceleration recorders (M01, M02 and M02A instruments) has been built up gradually since the first of these instruments was placed in the field in 1966. The instruments are divided between structural and ground sites. A typical building installation consists of three three-component recorders located at the basement, mid-height and roof levels with sometimes, as in the Vogel building, a "free-field" site outside but close to the building. The instruments are generally interconnected to trigger simultaneously and share common time-marks. The ground installations are usually single instruments either at free-field sites or in the basements of single - or double-storey buildings. While no very strong ground shaking has yet been recorded in New Zealand (the maximum ground acceleration measured on an MO instrument is $0.19 \mathrm{~g}$ ), a number of records of engineering interest have been obtained from both ground and structural sites. The results of computer processing of twenty three-component records have been published (3).

\section{THE STRUCTURE:}

Vogel building, the Head office of the Ministry of Works and Development in Wellington, is a 17-storey reinforced concrete frame structure with a central core designed to act as a shear beam. The building is supported on a massive box foundation. There is an annex up to the third-floor level designed to be separated from the rest of the structure by a seismic break. The roof is 51.2 metres above the ground floor, with a further 8.5 metres to the base of the foundation slab below the second basement level. Horizontal dimensions of the tower structure are 32.9 metres by 25.6 metres, with the central core 19.1 metres by 11.8 metres. Schematic structural drawings of the building are given in figure 1 which also shows the accelerograph locations in the basement, on the 8 th floor and on the 14 th (top) floor. The remote site instrument is in a manhole 15 metres from the corner of the building, 50 metres from the basement instrument. 


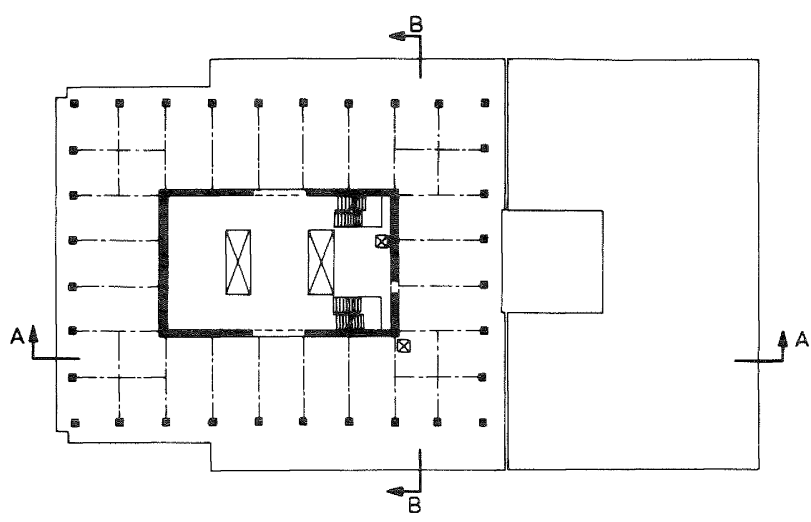

KEY: $\otimes$ Accelerometer locations

PLAN AT $3^{\text {rd }}$ FLOOR

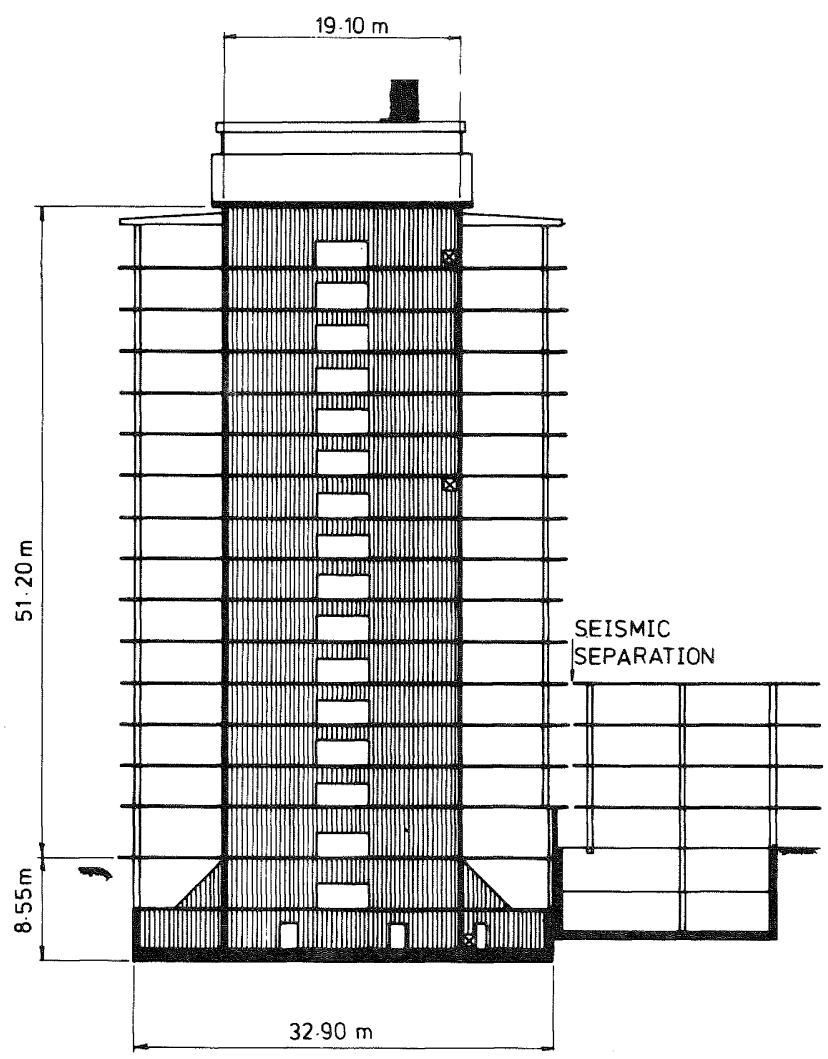

SECTION A-A

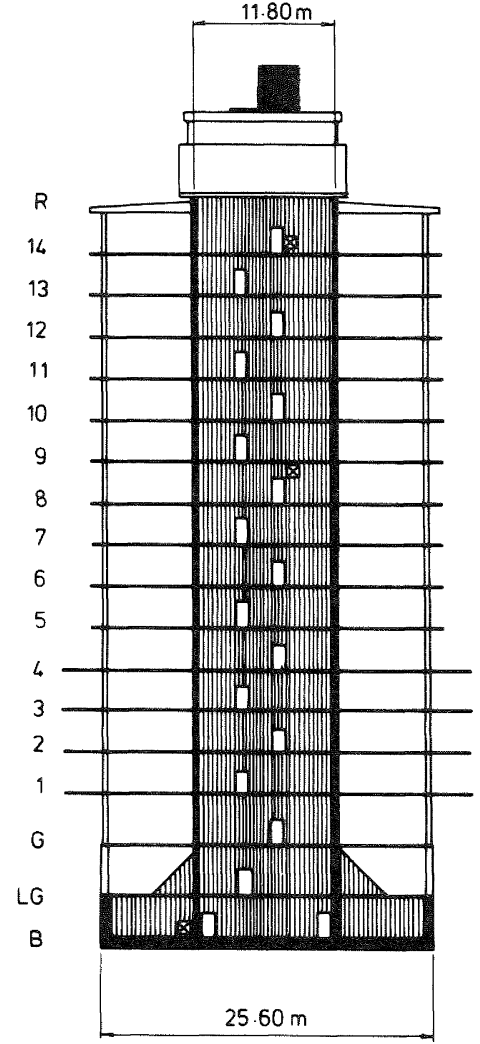

SECTION B-B

VOGEL BUILDING WELLINGTON

FIGURE 1: Schematic structural drawings of Vogel building showing the accelerograph locations. The remote site instrument (not shown) is 15 metres fram the corner of the building and 50 metres from the basement instrument. 
Forced vibration tests were performed on the structure in 1971 (15). The modal periods measured in the vibration tests are listed in Table 1.

\section{THE EARTHQUAKES:}

The Central North Island earthquake of 5 January 1973 was a deep shock located $173 \mathrm{~km}$ beneath Raetihi at an epicentral distance of $240 \mathrm{~km}$ from Wellington. It has been assigned a magnitude of 7.0 by the Seismological observatory (6) . Minor damage was widespread over the lower North Island, with the intensity exceeding MM6 around National Park and in Hawke's Bay. The felt area stretched from Kawhia and whakatane in the north to Hokitika and Timaru in the south. About $\$ 180,000$ was paid out on more than 2500 insurance claims by the Earthquake and War Damage Commission (13). As well as the Vogel building records, accelerograms from Atene on the Wanganui River and Massey University in Palmerston North have been published for this event (3), with many more under consideration for processing using PEL's new digitizing system.

The large magnitude of the earthquake and its distance from Wellington produced ground acceleration records at the Vogel building with little content at frequencies higher than $5 \mathrm{~Hz}$ (figure 2). The low frequency ground acceleration was very efficient in exciting the structure for which the recorded horizontal acceleration response was almost entirely in the first two modes in each direction. The maximum basement acceleration of $0.03 \mathrm{~g}$ at the Vogel site produced a roof response of $0.10 \mathrm{~g}$.

The Cook Strait earthquake was a much more local lower magnitude event. The magnitude 6.0 shock of 18 January 1977 was centred $64 \mathrm{~km}$ from Wellington at a nominal depth of $33 \mathrm{~km}$, out to sea $25 \mathrm{~km}$ east of Cape Campbell. Intensities reached MM VI to VII in the nearest land areas in north Marlborough, with 960 insurance claims, the most serious relating to damaged chimneys (14). The basement acceleration reached $0.08 \mathrm{~g}$ at the Vogel building, with a maximum roof response of $0.17 \mathrm{~g}$.

\section{COMPARISON OF THE REMOTE SITE AND BASEMENT} RECORDS:

In both earthquakes, the basement records were considerably attenuated with respect to the remote site records. This attenuation is evident in the list of peak horizontal accelerations in Table 2. The maximum basement accelerations lie between 0.54 and 0.85 of the corresponding peak remote site values.

The frequency dependence of the attanuation is apparent in figures 2 and 3 which show the Fourier amplitude spectra of the $\mathrm{S} 88 \mathrm{E}$ component of the basement and remote site records for the 1973 and 1977 earthquakes respectively. The spectra for the two sites are almost identical for frequencies up to about 1.1 Hz, which is slightly lower than the fundamental frequency of the building in this direction (about $1.3 \mathrm{~Hz}$ ). For frequencies higher than $1.1 \mathrm{~Hz}$ the basement records are generally attenuated with respect to the remote site records, often by a considerable amount. Even for frequencies as low as 1.5 and $1.9 \mathrm{~Hz}$, at which major peaks occur in the $\mathrm{S} 88 \mathrm{~F}$ component of both the remote site and basement spectra of the 1977 cook strait records, the basement site and basement spectra of the 1977 cook Strait records, the basement amplitudes are only $2 / 3$ and $3 / 4$ of the remote site amplitude. The comparison of the spectra of the S02W components generally shows similar behaviour. However, for the 1977 cook strait earthquake, the basement amplitude is larger than the remote site amplitude by a factor of about $4 / 3$ at the largest peak in both spectra which occurs in the frequency range of 1.5 to $1.6 \mathrm{~Hz}$.

Similar behaviour to that recorded at the Vogel building, with the basement records being attenuated with respect to those at a nearby free-field site and the attenuation increasing with frequency, has been studied for accelerograms from the basement and parking lot of the Hollywood Storage Building in the 1952 Arvin-Tehachapi and 1971 San Fernando earthquakes (4.5.8). The studies of the Hollywood Storage Building attempted to reconcile the differences between the free-field and basement records using the theoretical results for simple models of soilstructure interaction developed by Bielak (9) and Luco (10). Although some of the differences between the records could be explained, by no means all the discrepancies were accounted for. In particular, the theories did not predict the extent of the attenuation observed at the higher frequencies, possibly because they did not include the effects of embedment of the structure or non-vertically incident waves which can lead to a considerable reduction of the motion. Solutions for models incorporating these features are too complicated to use for the inverse problem of deriving the model parameters from earthquake records to explain a quantitative way the differences between measured free-field and basement records.

In the present study, a different approach is taken. Although the differences between the basement and remotesite accelerograms show that soilstructure effects are appreciable, an attempt is made to reproduce the recorded responses using conventional rigid-base linear modal models. The rationale behind this approach is that linear modal analysis rather than a complicated soil-structure analysis is more likely to be used during design, so it is important to verify that this type of analysis is capable of reproducing the recorded motions. It is usually only for very special structures that soil-structure interaction models are used explicitly. If fixed-base modal analysis is shown to be applicable, it is important to determine whether free-field or basement sites for which 


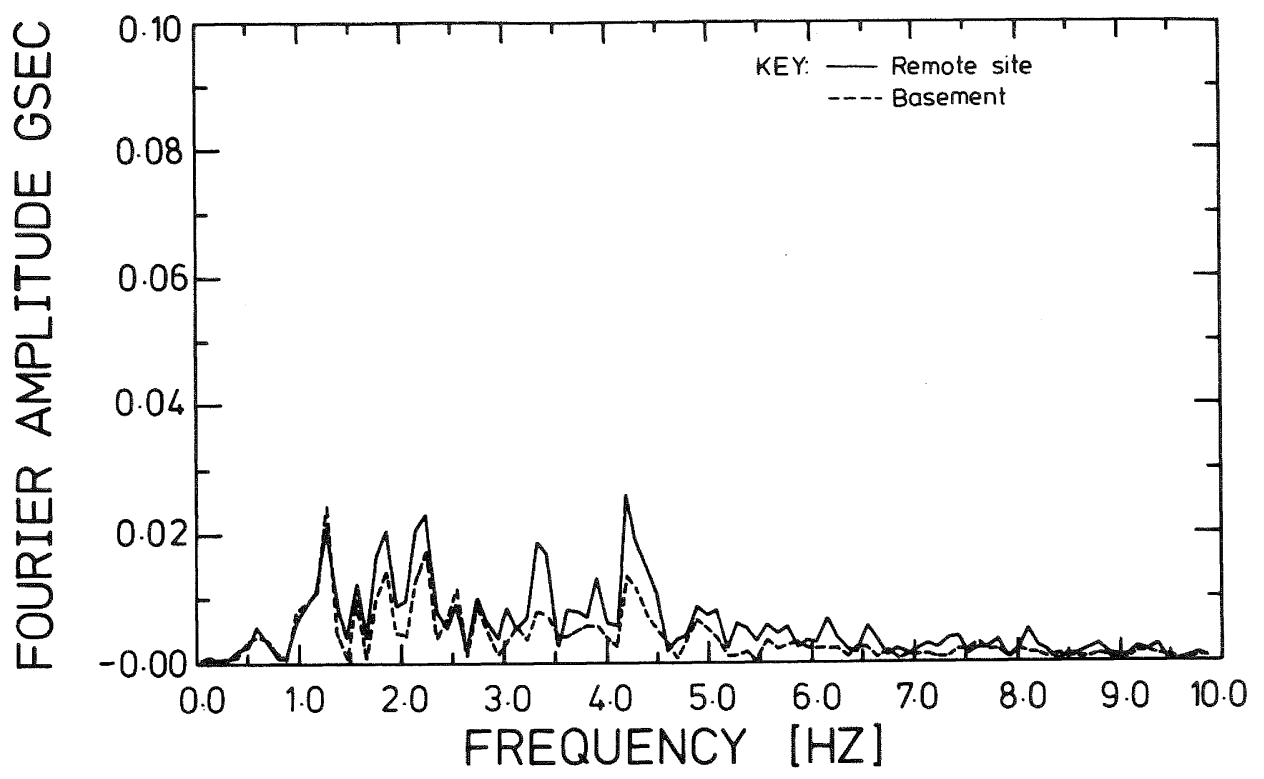

FIGURE 2: Fourier amplitude spectra of the remote site and basement accelerations, Vogel building, Central North Island earthquake, 5 January 1973, S88E (longitudinal) component.

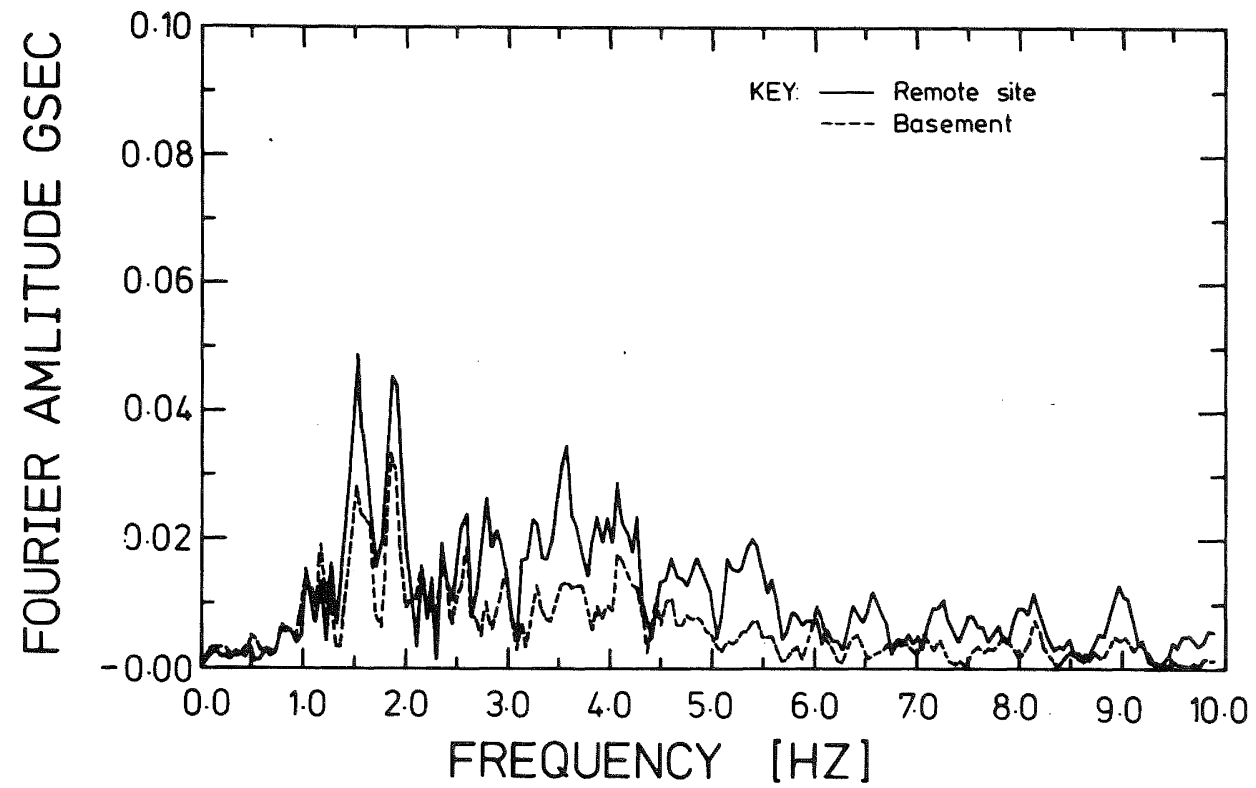

FIGURE 3: Fourier amplitude spectra of the remote site and basement accelerations, Vogel building, Cook Strait earthquake, 18 January 1977, S88E component. 
the higher frequency components of the acceleration are modified yield records which are more relevant as design

earthquake motions. In the present study. the measured remote-site and basement accelerations are evaluated as alternative excitations.

\section{THE IDENTIFICATION TECHNIQUE:}

Rigid-base, planar, linear models possessing classical normal modes are considered. The equations of motion for the response of an $R$ degree-of-freedom model of this type to a ground acceleration $\ddot{z}$, which in the Vogel building study is taken as either the remote site or basement acceleration, may be written in terms of uncoupled modal equations. For the rth mode relative displacement at position, $\mathrm{p}, \mathrm{x}_{\mathrm{pr}}$ '

$\ddot{x}_{p r}+2 \rho_{r} w_{r} \dot{x}_{p r}+w_{r}^{2} x_{p r}=-c_{p r} \ddot{z}$

The total response at $\mathrm{p}$ for the displacement relative to the ground, $x_{p}$ is the sum of the modal contributions.

$x_{p}(t)=\sum_{r=1}^{R} x_{p r}(t)$

The parameters of the rth mode are the fraction of critical viscous damping $f_{r^{\prime}}$, the modal frequency $\mathrm{w}_{r^{\prime}}$, and the effective participation factor at position $\mathrm{p}, \mathrm{C}_{\mathrm{pr}}$ :

$\mathrm{C}_{\mathrm{pr}}=\Phi_{\mathrm{pr}}\left({\underset{\sim}{\Gamma}}_{\Gamma}^{\mathrm{T}} \underline{\mathrm{M}}\right) /\left({\underset{\sim}{\Gamma}}_{\Gamma}^{\mathrm{T}}{\underset{\sim}{\mathrm{M}}}_{\Gamma}\right)$

Here $\Phi_{p r}$ is the value of the rth

mode shape at $p, \underset{\sim}{\phi}$ if the rth mode shape vector, $M$ is the mass matrix of the structure, and every component of the column vector 1 is unity. It can be shown that $\mathrm{C}_{\mathrm{pr}}$, which is independent of the normalization of $\Phi_{r}$ ' is the information about the rth mode $\sim r^{\prime}$ shape which can be determined uniquely from the ground excitation and the response at $p$ (l); in general the complete mode shape $\phi_{r}$ cannot be determined from measurements of the response at a limited number of locations, which in turn prevents unique estimation of the stiffness and mass matrices.

The identification is performed by selecting the parameters of the $R$ modes to achieve a frequency-domain least-squares match over a selected frequency band between the complex-valued Fourier transforms of the measured acceleration response and the theoretical response to the recorded excitation. The frequencydomain least-squares match is practically equivalent to one in the time domain if all the significant response is included in the identification frequency band.

OPTIMAL TWO-MODE MODELS FROM THE EARTHQUAKE RECORDS:

Two-mode models of the Vogel building for the S02W and S88E direction were derived from both the 1973 and 1977 earthquake records using the remote site and basement records as excitation. For the 1977 records both the 8 th and 14 th floor responses were matched, while only the 14 th floor responses were available from the 1973 earthquake. Comparisons of the acceleration histories of the measured 14 th floor response and that calculated for the optimal model using the basement input are shown in figure 4 for the S88E component of the 1973 earthquake, with the corresponding Fourier amplitude spectra in figure 6 . The results are summarised in Table 3, which gives the optimal values of the parameters, the mean square error $\mathrm{J}$ between the measured and model acceleration over the identification frequency band normalised by the mean square acceleration response over the same frequency range, and the shifts needed to align the input and response records. A positive shift $\Delta$ means that time zero on the response record corresponds to time $\Delta$ on the input record. The shifts are required because of a slight lack of synchronization between the digitized records from different locations in the Vogel building arising from difficulties in determining common time-marks at the beginning of the film records. The normalised value of $J$ of 0.016 for the $S 88 \mathrm{E}$ component in the 1973 earthquake is the best yet achieved for an essentially full-duration record.

The periods estimated from the 8 th floor and 14 th floor responses for the same input motion are consistent. The periods estimated using the remote site inputs are usually slightly longer than those estimated from the basement excitations. The fundamental periods estimated from the earthquake response are about twenty percent longer than those measured in the handshaking vibration tests performed in 1967 for the S88E direction. In the S02W direction, the earthquake periods are about ten to fifteen percent longer than the handshaking values for the fundamental mode, and six to ten percent longer than those measured in forced vibration tests. lengthening of the fundamental mode period from vibration test values has been observed in the earthquake response of many buildings. The periods of some of the Los Angeles buildings studied using the same identification technique $(2,11)$ lengthened by thirty percent for similar or smaller levels of excitation and response, for example the 1900 Avenue of the Stars building in the San Fernando earthquake (0.14 g response) and JPL Building 180 in the Borrego Mountain ( $0.03 \mathrm{~g}$ response) and Lytle Creek (0.04 g response) earthquakes.

There is much less consistency in the dampings estimated from the two response locations (8th and 14 th floors) and the various excitations (the basement and remote site records for the two earthquakes) than for the periods. The values for the fundamental s02W mode using the remote site inputs appear low, all less than one percent. The values of 1.0 to 1.5 percent estimated from 


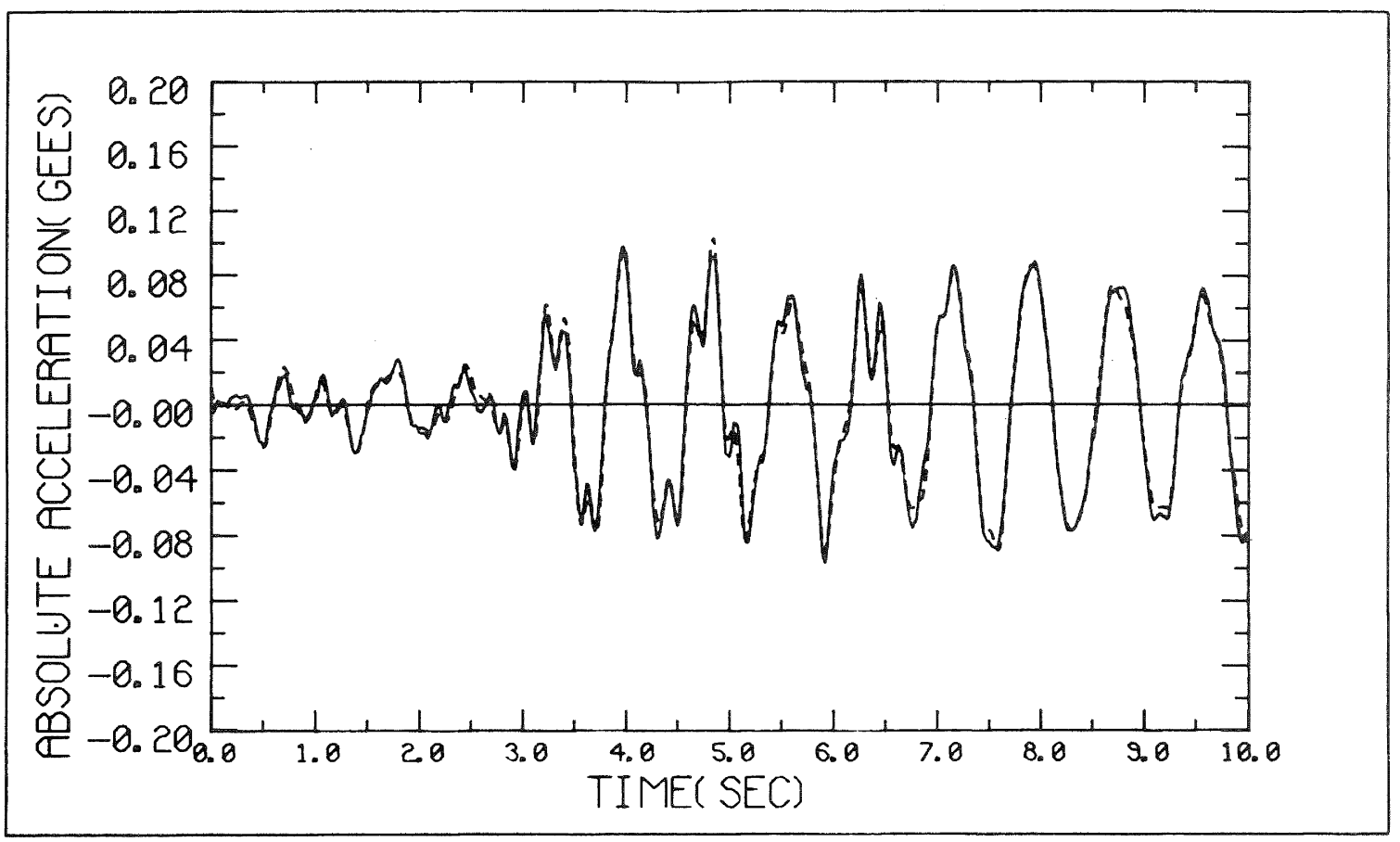

FIGURE 4: Measured 14th floor acceleration (-) and that calculated (--) for the optimal 2-mode basement excitation model, 1973 earthquake, S88E component.

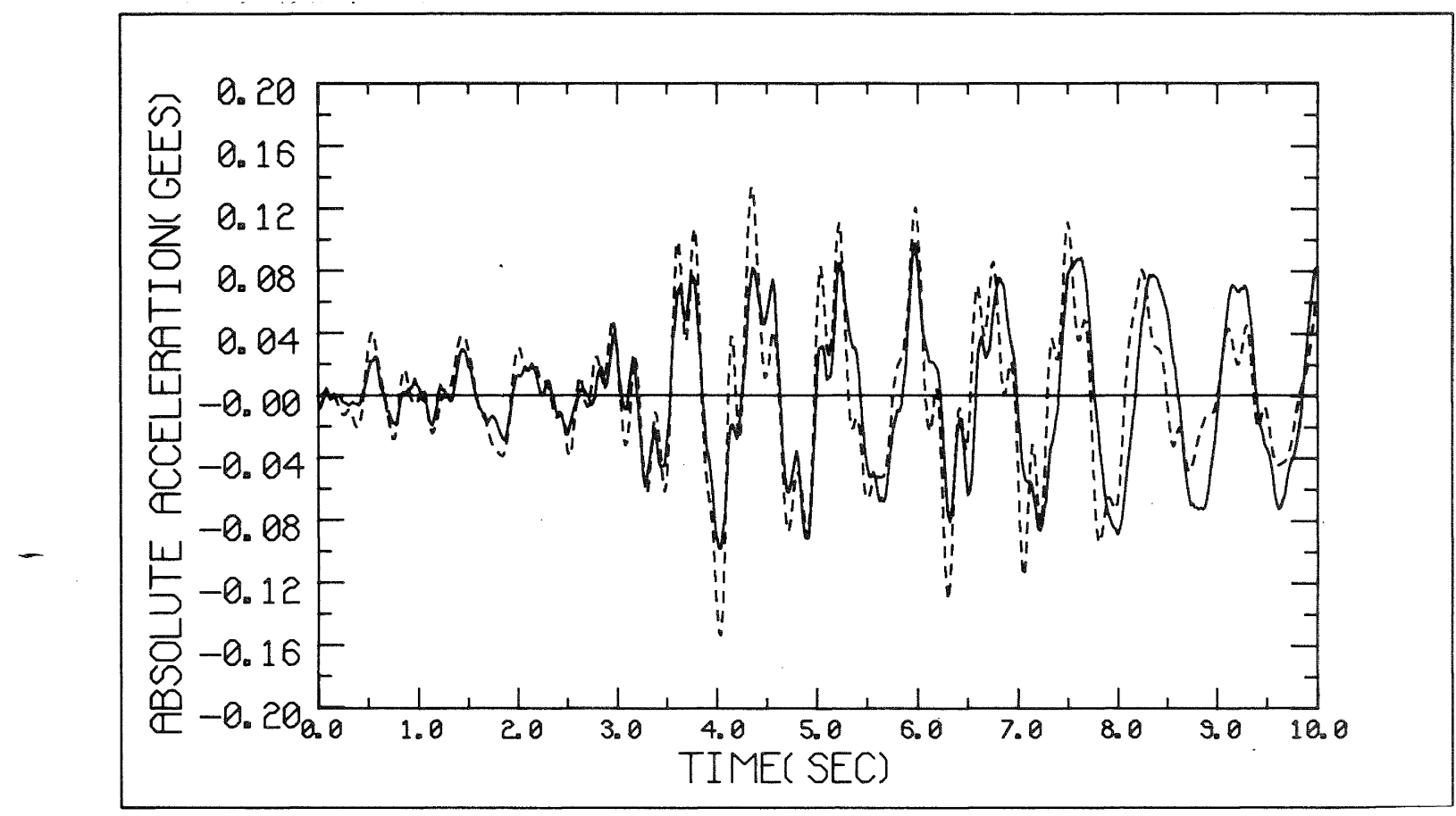

FIGURE 5: Measured 14th floor acceleration ( - ) and that calculated (--) for the optimal basement excitation model of Figure 4 subjected to the remote site acceleration, 1973 earthquake, S88E component. 
the basement excitations are also considerably less than the dampings estimated for reinforced concrete structures in the San Fernando earthquake, although admittedly most of those structures suffered double the excitation and response levels of Vogel building. However, the dampings of Vogel building identified from the S02W earthquake records are also less than the value of 2.4 percent estimated from the free vibration decay of the motion induced by hand-shaking during the 1967 tests, while it is expected that the damping from the larger amplitudes of the earthquake motions should be greater than in the vibration tests. The values of 3 percent estimated from the S88E records seem more realistic, although still lower than the values of around 7 percent estimated for undamaged reinforced concrete structures from the San Fernando records. As with the damping, there are considerable variations in the values of the participation factors estimated from the various combinations of response and input records.

For all the response records, the optimal model with basement input provides a better match than the optimal remote site input model. For the S88E components, the improved match of the basement input models may be from a better fitting of the second mode response around $5 \mathrm{~Hz}$. Despite the basement records being deficient in the 4 to $6 \mathrm{~Hz}$ range compared to the remote site records, the optimal models using the basement excitations are still able to reproduce the second mode peaks in this range (Figure 6 ).

The differences in the responses of the optimal basement input and remote site input models are less than might be expected from the differences in the excitations. One reason is that most of the differences in the remote site and basement excitations occur at frequencies higher than the fundamental of the structure, and the fundamental mode contributes the major part of the response for these records. Another reason for the small differences in the responses for the optimal models for the alternative inputs is that the model parameters have been selected to match the measured response as closely as possible. The optimal model parameters, especially for the dampings, for the remote-site excitation models are not those that would be expected for a rigid-base model in the absence of interaction. For the design situation, where it is wished to select either the remote site or basement record as the excitation, a better appreciation of the effects of the difference in the inputs on the calculated response can be achieved by subjecting the optimal basement input model to the remote-site excitation. A plot of the measured roof acceleration and that calculated in this way is shown in Figure 5 for the 1973 S88E component. The calculated maximum acceleration response exceeds the measured value by about 60 percent. The plot can be compared to the optimal match in Figure 4

CONCLUDING REMARKS:

The massive foundation slab of the seventeen-storey Vogel building in Wellington has caused marked differences in the earthquake acceleration records obtained in the basement and at a nearby "freefield" site. The basement records are attenuated with respect to the remote-site records for most frequencies above $\mathrm{I} \mathrm{Hz}$. Excellent matches of the recorded response of the structure have been achieved by calculating the response of two-mode linear rigid-base models to the recorded excitations, with the modal parameters of the models identified from the earthquake records. In all cases, using the basement rather than the remote site record as the excitation has produced a better match of the recorded response.

For the Vogel building, the differences in the responses calculated for the optimal basement and remote-site excitation models are not great, since the differences in the excitations occurred at higher frequencies than the dominant part of the response, which was mainly in the fundamental mode in each direction. However, similar modifications of the remote site record in the basement of a building with a fundamental period around 0.2 to 0.3 seconds, typical of many one- to three-storey buildings, would have a marked effect on the response. In this period range the basement accelerations in the vogel building were considerably reduced from the remote-site accelerations, leading to an expected substantial reduction in the response of a building with a short fundamental period constructed on a solid foundation slab.

A project is under consideration to instrument some short-period structures with remote-site and basement accelerographs to determine whether there is the same type of reduction of the free-field accelerations in the basement, with a consequent reduction of the response, as measured for the tall Vogel building. This is necessary to confirm that it is the basement slab that has the major effect on modifying the excitation, rather than a feedback mechanism between the superstructure and the soil, which is likely to be less pronounced for a lower, lighter structure. At the moment in the New Zealand strong-motion network, there is basement and remote-site instrumentation only for a few tall structures.

An ideal program to study the effects of basement attenuation in short-period buildings would provide interconnected basement and roof instruments in neighbouring one- to two-storey buildings, one on a solid foundation and the other on a light foundation, and an instrument at a nearby free-field site. As a minimum, interconnected free-field and basement instruments in a short building with a heavy foundation slab should be established. There are arguments for using digital accelerographs so quantitative information can be obtained from minor shaking sufficient to trigger the instruments but too small to allow accurate digitization of film records. These instruments should be set up on flexible soil conditions, where the effects are likely to be more marked, in an area where records are likely 


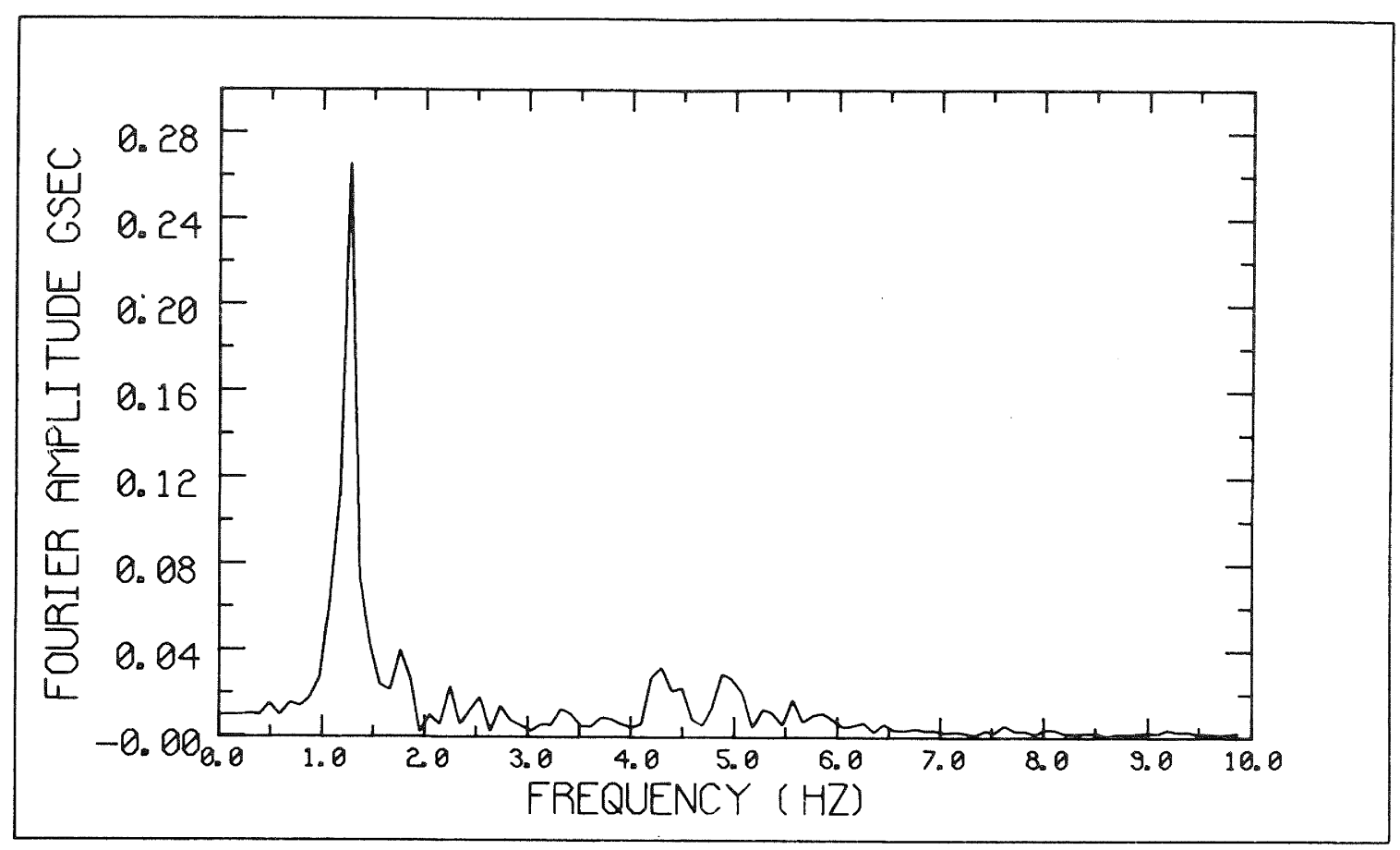

(a)

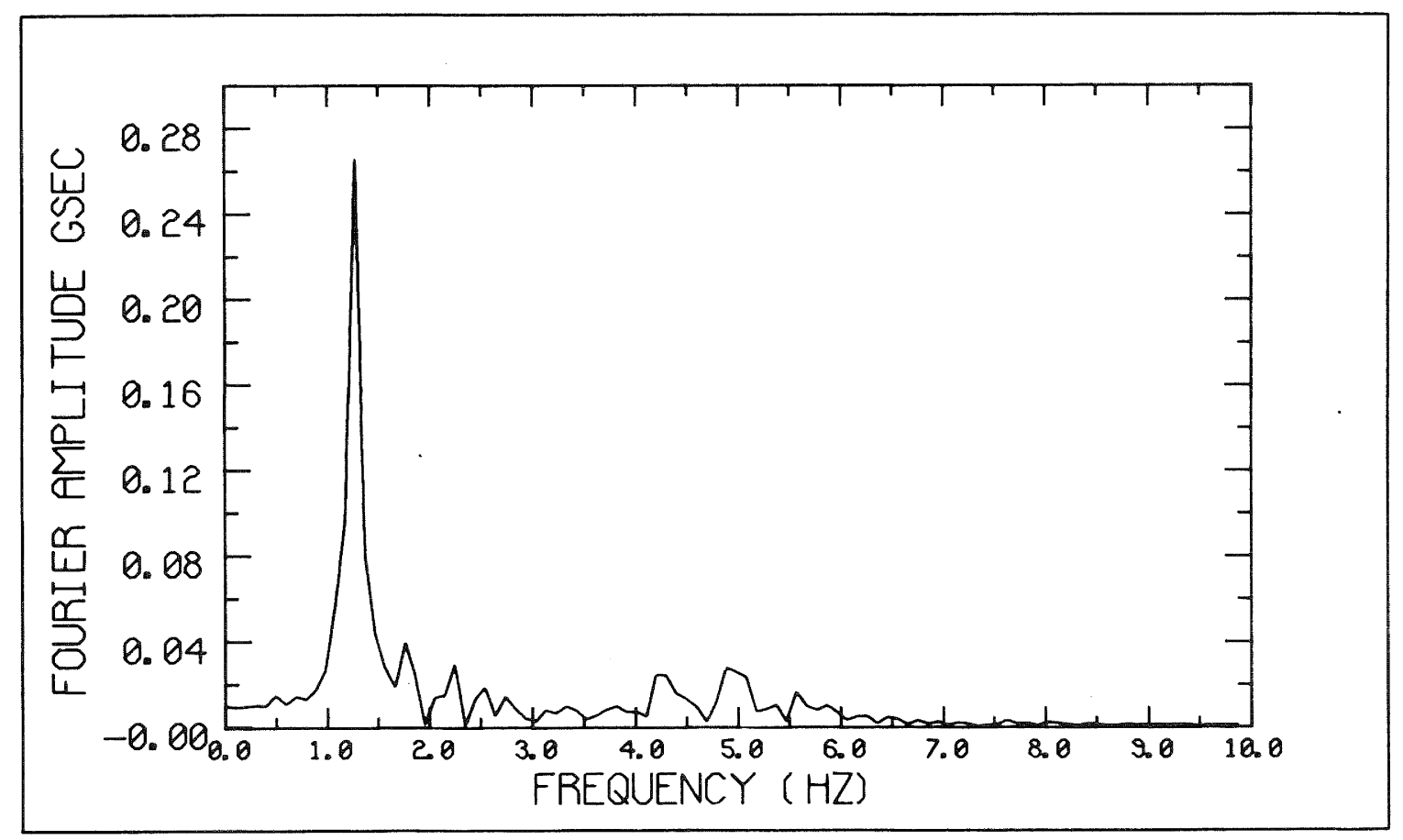

(b)

FIGURE 6: Fourier amplitude spectra of the 14th floor acceleration, Vogel building, 1973 earthquake, S88E component
a) Measured spectrum ;
b) Spectrum of the optimal 2-mode basement excitation model response, almost identical to the measured spectrum. 
to be obtained within a few years. The Marewa site at Napier, for which ground records with maximum horizontal components of $0.13 \mathrm{~g}$ and $0.11 \mathrm{~g}$ have been obtained in 1980 and 1982, or a site in the Hutt Valley appear suitable for this type of study.

\section{REFERENCES :}

1. Beck, J.L. (1978). Determining Models of Structures from Earthquake Records. EERL Report 78-01, Caltech, Pasadena.

2. Beck, J.L., G.H. McVerry and P.C. Jennings (1980). Applications of System Identification Techniques to Recorded Earthquake Responses, Proc. 7WCEE, Vol 6, pp 49-56, Istanbul.

3. Beck, J.L., P.M. Randall and R.T. Hefford (1981). Computer Analyses of New Zealiand Earthquake Accelerograms, Vol. I, PEL, DSIR, Lower Hutt.

4. Crouse, C.B. and P.C. Jennings (1975). Soil-Structure Interaction During the San Fernando Earthquake, Bull. Seism. Soc. Am., Vol. 65, pp 13-ff.

5. Duke, C.M., J.E. Luco et al (1970). Strong Earthquake Motion and Site Conditions : Hollywood, Bull. Seism. Soc. Am., Vol. 60, pp $1271-89$.

6. Haines, A.J. (1981). Systematic Effects of the Introduction in 1977 of a New Magnitude Scale for New Zealand Earthquakes, NZ J. Geol. and Geophys., Vol. 24, pp 141-53.

7. Hefford, R.T., P.M. Randall et al (1979). The New Zealand StrongMotion Earthquake Recorder Network, Bull. NZ Nat. Soc. Eq. Eng., Vol. 12, pp 256-63.

8. Housner, G.W. (1957). Interaction of Building and Ground During an Earthquake, Bull. Seism. Soc. Am. Vol. 47, pp 179-86.

9. Jennings, P.C. and J. Bielak (1973). Dynamics of Building-Soil Interaction, Bull. Seism. Soc. Am., Vol. 63, pp $9-48$.

10. Luco, J.E. (1969) Dynamic Interaction of a shear wall with the Soil, ASCE J. Eng. Mech. Div., Vol. 95, pp $333-46$.

11. McVerry, G.H. (1979). FrequencyDomain Identification of Structural Models from Earthquake Records, EERL Report 79-02, Caltech, Pasadena.

12. McVerry, G.H. (1980). Structural Identification in the Frequency Domain from Earthquake Records, Eq. Eng. and Struct. Dyn., Vol. 8, pp $161-80$

13. New Zealand Seismological Report 1973, Geophysics Division, DSIR, Wellington.
14. New Zealand Seismological Report 1977, Geophysics Division, DSIR, Wellington.

15. Stephenson W.R. and R.I. Skinner (1973). A System for Measuring Normal Modes of Structures, Proc. 5WCEE, Vol. 2, pp 1521-4, Rome. 
TABLE 1 : VIBRATION TEST PROPERTIES OF VOGEL BUILDING

MAN-EXCITED TESTS FEBRUARY 1967

LONGITUDINAL (S88E)

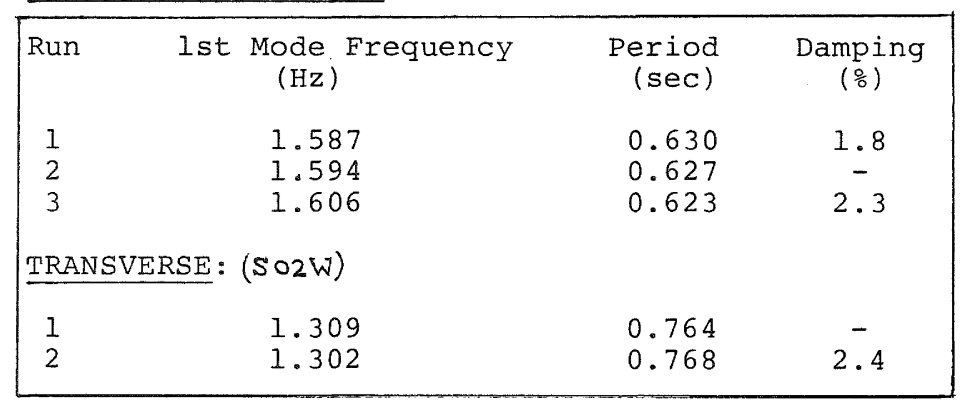

MACHINE-SHAKING TESTS JUNE 1971

\begin{tabular}{|ccccc|}
\hline \multicolumn{2}{ll}{ TRANSVERSE } & $(\mathrm{SO2W}):$ & & \\
\hline Mode & $\begin{array}{c}\text { Frequency } \\
(\mathrm{Hz})\end{array}$ & $\begin{array}{c}\text { Period } \\
(\mathrm{sec})\end{array}$ & $\begin{array}{c}\text { Participation Factor (*) } \\
\text { 14th Floor }\end{array}$ & 8th Floor \\
1 & 1.266 & 0.79 & 1.48 & 0.82 \\
2 & 5.68 & 0.176 & -0.67 & 0.68 \\
\hline
\end{tabular}

(*) Calculated from measured mode shape and floor lumped-mass distribution.

TABLE 2 : PEAK HORIZONTAL ACCELERATIONS IN VOGEL BUILDING

\begin{tabular}{|c|c|c|c|c|c|}
\hline $\begin{array}{l}\text { EARTHQUAKE } \\
\text { COMPONENT }\end{array}$ & REMOTE & BASEMENT & $\frac{\text { BASEMENT/ }}{\text { REMOTE }}$ & 8 th FLOOR & 14th FLOOR \\
\hline \multicolumn{6}{|l|}{-1973} \\
\hline $\begin{array}{c}\mathrm{N} 02 \mathrm{E} \\
\text { N88W } \\
\text { Horizontal }\end{array}$ & $\begin{array}{l}390 \mathrm{~mm} / \mathrm{sec}^{2} \\
430 \\
550(\mathrm{~N} 46 \mathrm{E})\end{array}$ & $\begin{array}{l}270 \\
250 \\
310(N 32 E)\end{array}$ & $\begin{array}{l}0.69 \\
0.58\end{array}$ & & $\begin{array}{l}780 \\
960 \\
1020(N 44 W)\end{array}$ \\
\hline \multicolumn{6}{|l|}{1977} \\
\hline $\begin{array}{c}\mathrm{N} 02 \mathrm{E} \\
\mathrm{N} 88 \mathrm{~W} \\
\text { Horizontal }\end{array}$ & $\begin{array}{l}780 \\
830 \\
1100(\mathrm{~S} 50 \mathrm{~W})\end{array}$ & $\begin{array}{l}660 \\
450 \\
800(\mathrm{~S} 36 \mathrm{~W})\end{array}$ & $\begin{array}{l}0.85 \\
0.54\end{array}$ & $\begin{array}{l}450 \\
820 \\
870(\mathrm{~S} 66 \mathrm{~W})\end{array}$ & $\begin{array}{l}1000 \\
1600 \\
1700(\mathrm{~S} 64 \mathrm{~W})\end{array}$ \\
\hline
\end{tabular}

TABLE 3 : OPTIMAL TWO-MODE MODELS OF VOGEL BUILDING

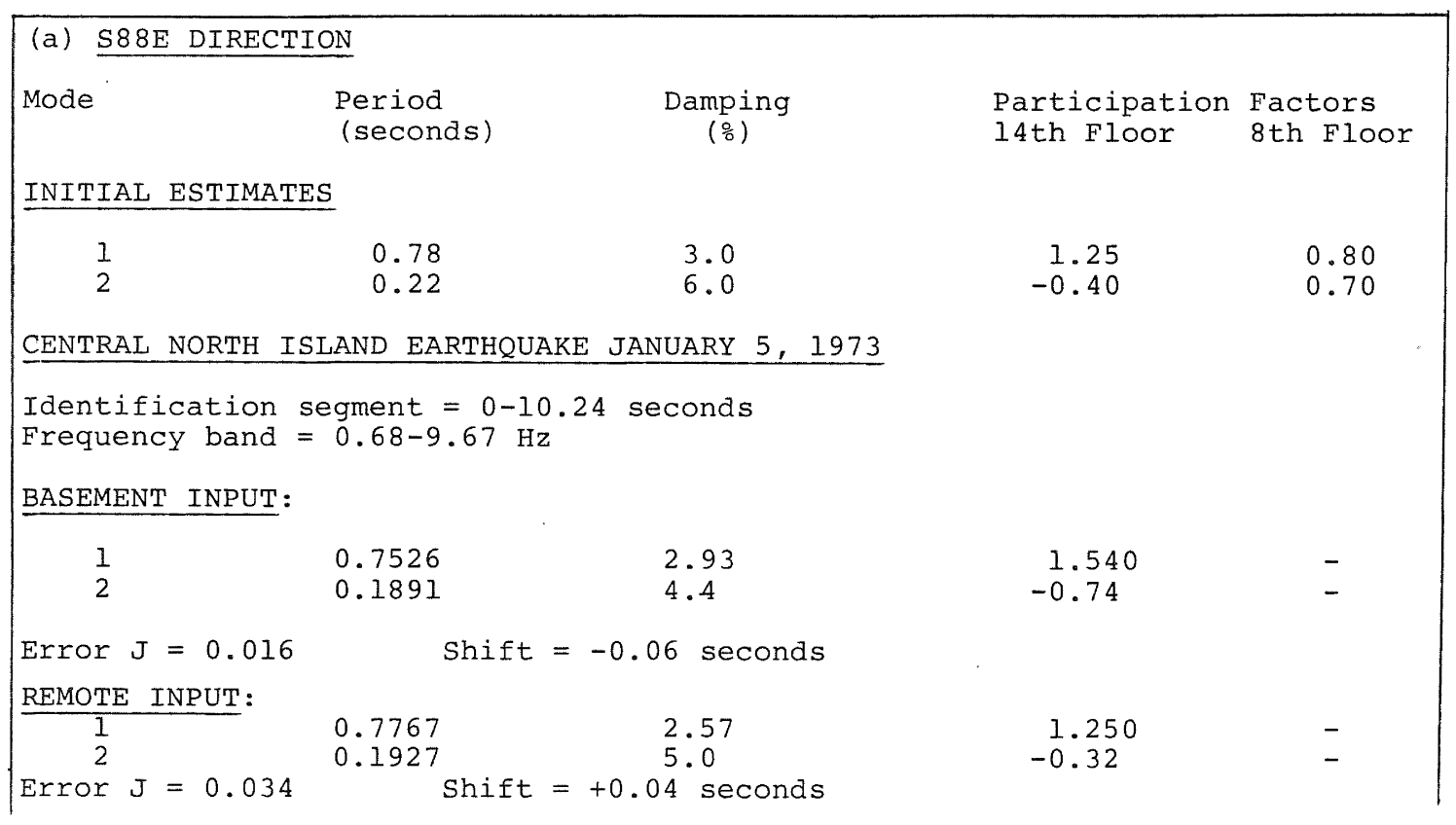


TABLE 3 : OPTIMAL TWO-MODE MODELS OF VOGEL BUILDING Cont'd

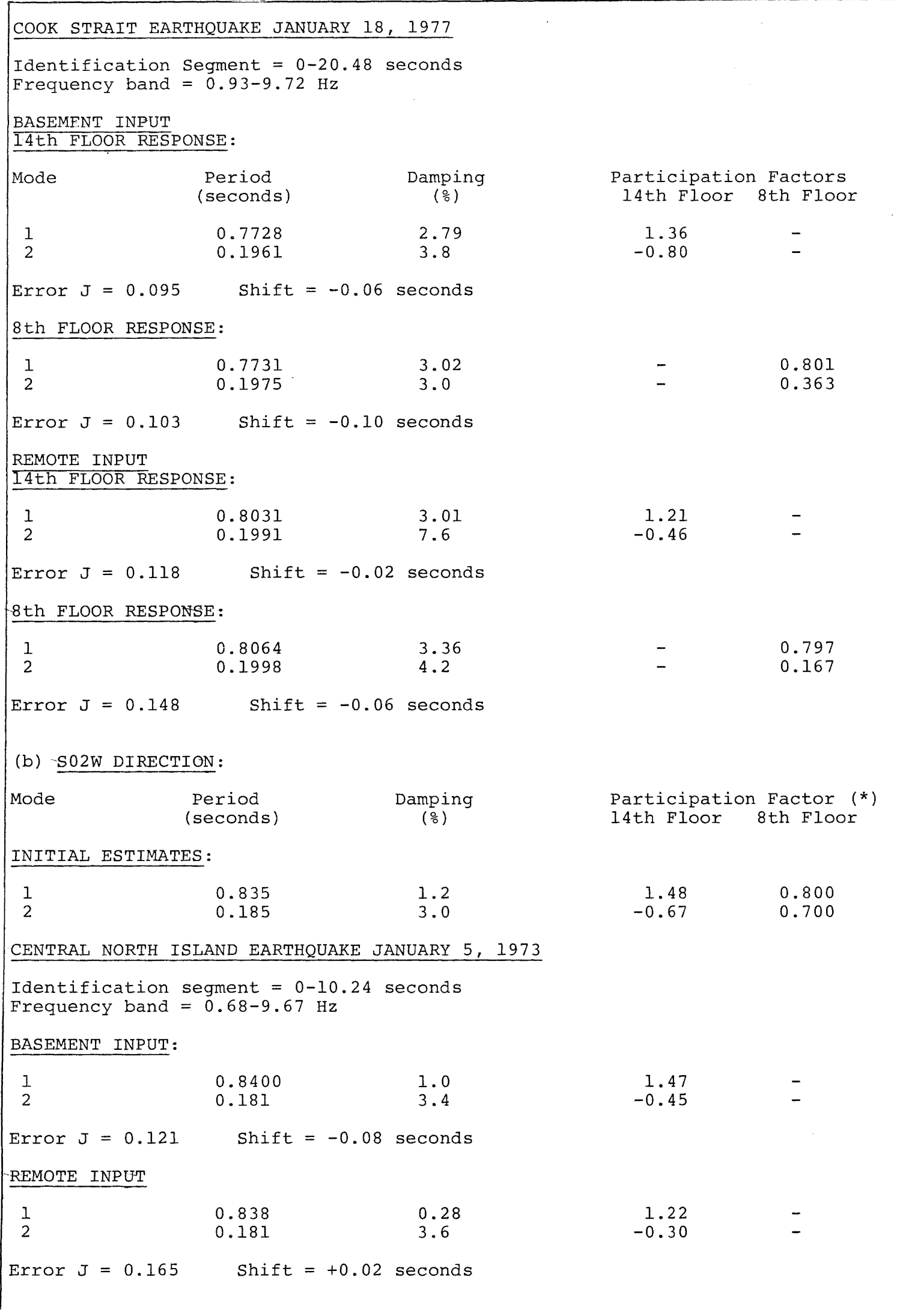


TABLE 3 Cont'd...

COOK STRAIT EARTHQUAKE JANUARY 18,1977

Identification segment $=0-20.48$ seconds

Frequency band $=0.93-9.72 \mathrm{~Hz}$

BASEMENT INPUT

I-4 Th FLOOR RESPONSE:

$\begin{array}{lll}1 & 0.8494 & 1.48\end{array}$

$\begin{array}{lll}1 & 0.1838 & 1.48\end{array}$

1.39

$-0.35$

$-$

Error $J=0.215$ Shift $=-0.06$ seconds

8th FLOOR RESPONSE:

$\begin{array}{lll}1 & 0.8443 & 1.11 \\ 2 & 0.1832 & 1.5\end{array}$

$-\quad 0.703$

Error $\mathrm{J}=0.282 \quad$ Shift $=-0.12$ seconds

REMOTE INPGT

14 th FLOOR RESPONSE:

$\begin{array}{rrrrr}1 & 0.8845 & 0.66 & 1.27 & - \\ 2 & 0.1906 & 3.1 & -0.22 & -\end{array}$

Error $\mathrm{J}=0.284 \quad$ Shift $=-0.02$ seconds

8.th FLOOR RESPONSE:

$\begin{array}{lllll}1 & 0.8793 & 0.20 & - & 0.718 \\ 2 & 0.1876 & 3.8 & - & 0.129\end{array}$

Error $J=0.312 \quad$ Shift $=-0.08$ seconds 